\title{
INTEGRATING DIGITISATION, MONITORING AND SELF-ORGANISATION SKILLS INTO INTEGRATED DESIGN ENGINEERING EDUCATION
}

\author{
Andreas EIDEN ${ }^{1}$, Yannick JURESA ${ }^{1}$, Jens GÖBEL ${ }^{1}$, Roman TUETSCH ${ }^{2}$, Kristine \\ $\mathrm{KLAEGER}^{3}$ and Katharina GRIES ${ }^{4}$ \\ ${ }^{1}$ Institute of Virtual Product Engineering, TU Kaiserslautern, Germany \\ 2Institute for Mechanical and Automotive Design, TU Kaiserslautern \\ ${ }^{3}$ Didactics of Biology, TU Kaiserslautern \\ ${ }^{4}$ Selbstlernzentrum, TU Kaiserslautern
}

\begin{abstract}
Mechanical engineering curriculums at German universities have mostly theoretical approaches to design theory. Several institutes and chairs have specialized courses regarding this topic, but these are seldomly integrated. The approach IDEE - Integrated Design Engineering Education - brings the specialized fields on design theory together in one course with a highly practical focus at the beginning of the mechanical engineering studies. This is realized by a mixture of theoretical lectures and a group project. For students, this includes their first experience of a complex group project with peers and also the first oral presentation in an engineering context. With a lack of professional and soft skills, there is often friction inside groups. There is also a need for appropriate tools to work collaboratively. Due to the Corona pandemic, lectures and the group project must be held completely online.

This paper describes our approach in helping the students improve their professional and personal skills by integrating new courses within the project, monitor their group dynamics, and also use digitisation to provide an online-only solution. This paper presents the challenges regarding soft skills and collaborative work as well as the chosen approach on how to integrate digitisation, monitoring, and selforganisation skills into the lecture to face the challenges.
\end{abstract}

\section{Keywords: Digitisation, self-organisation, project-management, monitoring}

\section{INTRODUCTION}

Classical mechanical engineering curriculums teach design contents in theoretical lectures during the first semesters and lack practical activities. Students often do not draw connections between lectures and struggle with exams, as these only focus on the repetition of this theoretical knowledge. Since the Bologna process, more and more attention has been paid to competence orientation in degree programmes. Generic competencies such as communication skills, problem-solving abilities, and selfdirected, cooperative work are becoming increasingly important alongside subject-specific competencies [1]. For this reason, the lecture IDEE - Integrated Design Engineering Education - was created. It connects methods and knowledge from different fields to give insights into product development and complex processes while working in interdisciplinary teams. The lecture is given in the second semester, when students are quite new and at the start of the curriculum.

Over four weeks, we teach several bits of theoretical information, that are needed for a design project, for instance, there are lectures in Design Theory, Mechanical Design, Computer-Aided-Design (CAD), and Project Management. During IDEE, there are just some small bits of information, as all these topics are afterwards given as a full lecture during the bachelor curriculum. The students (appox. 150 in total) are organized into groups of about $10-15$ while having three months to finish their design project from scratch. During this period, the groups have 6 meetings with their tutors - researchers from different mechanical engineering disciplines - to review their progress and discuss the next steps. In the end, each group must present their work in form of a business pitch to professors and researchers. They should highlight design aspects, as well as special features, that could convince potential customers to buy their respective products. The main idea is not having a perfectly designed product at this point, but to give 
the students a first insight into the daily work of designers and explore working in a group of peers to strengthen their soft skills. It is also the first time for many to work in an intercultural team, as $10 \%$ of the students are internationals, especially from China, Cameroon, and Rwanda, while $90 \%$ of the students have an educational background from German-speaking countries.

The project was awarded a price for excellent concepts in teaching by the German conference of ministries of education and by the donors' association for the promotion of humanities and sciences in Germany in the year 2009.

\section{ChAllenges}

In the last years, the students did quite well in building their first design projects, but in a more stressful and difficult way than we imagined. There are different reasons, why the project is so challenging for the students. First, there is a huge gap at the professional level. The students only have short introductory lectures for the different fields of engineering, design, and project management, as it is impossible to fully teach all aspects at this point of their studies. This leads to an overwhelming situation for all students, as they cannot develop professional competencies on that basis.

Second, students also lack soft skills. Since this project is the first group work with randomly selected peers from different cultural origins, there were often friction and miscommunication, which resulted in controversies. During the project management lecture, we shared some information about communication and conflict management, but the students could not use this knowledge on their own within the project teams. For efficient cooperation inside such groups, it is not sufficient to just have professional competencies. It is necessary to develop ideas, test them, and, if necessary, discard them. Compromises have to be found and it is important to work constructively on problem-solving. Many factors determine group performance such as group composition, the role of members, group size, etc. However, at the end of the day, the basic social, methodological, and personal competencies of individual team members and the team leader determine the performance of the group.

These competencies include self-organisation, self-reflection and self-motivation, teamwork and critical thinking skills, empathy, and type-appropriate communication as well as analytical thinking and presentation techniques.

During the final presentation, many students had difficulties focussing while giving a presentation, how to choose the right mixture of text and images and how to address the audience. Some, but not all students have these competencies, so that a random group could be chosen, where all students had a systemic lack of these skills.

Most of the time, tutors could assume the presence of problems in groups, but the students did not communicate them publicly, while there was no way to gain insight into the hidden dynamics inside the groups.

A third challenge is tools for collaborative work. There are three deliverables at the end of the design project: The students must upload a fully connected CAD model, a presentation of their work, and documentation with all requirements, functional logic and product architecture, mechanical dimensioning, and other project-related documents. At last, the Corona pandemic forced us to realize this course entirely online.

\section{IMPLEMENTATION AND EVALUATION OF SOFT SKILLS AND DIGITISATION}

Hence the biggest challenge mentioned previously is social and self-organisational skills of the students, we searched for partners to add specialized training to the course. At the TU Kaiserslautern, the SelfLearning Center (SLZ) offers various programmes to support students. By taking part in these offerings, students can strengthen their self-directed learning and self-organisation skills. Within the framework of the BMBF (German Federal Ministry of Education and Research) project "Selbstlernförderung als Grundlage. Die Förderung von Selbstlernfähigkeiten als integratives Konzept universitärer Lehre" (promoting self-learning approaches as an integral part of university teaching), we set up some additional courses in the project. Their objective is to build up specific competencies within the project, as well as generic competencies, which are promoted directly and indirectly. Most of the implementation was done in 2019, before the Covid19-pandemic and adapted to online-only in 2020. 


\subsection{Presentation Skills}

The course has been expanded in 2019 to enhance the presentation skills of the students. While in the first step, all students received theoretical input in form of a lecture, and those who were chosen to present the project were given the chance to practice their presentation skills in front of an audience. Their performance was filmed and rated in real-time by their peers with the Live Feedback tool. Live Feedback is a web-based feedback tool developed and implemented in the Department of Didactics in Biology at the TU Kaiserslautern within the BMBF project U.EDU: Unified Education. Via a web interface, Live Feedback enables the capture and recording of feedback data by clicking a "thumb-up" or "thumbs-down" button during the presentation from any smartphone, tablet, or computer. Statistically processed and visualized, the feedback can be displayed over a timeline and the associated scenes of the presentation can be called up by clicking on the timeline. With the help of this feedback recording, tutors from the SLZ consulted the students on how to improve the presentation skills and avoid mistakes. Aside from this individual feedback, the SLZ offered a one-day workshop, in which the students who presented their project learned about presentation methods and could further improve their skills.

At the end of the project, those students who already presented at the beginning were asked again to give a presentation, this time on the business pitch of their project. These presentations were recorded and rated again and tutors from the SLZ analysed the improvements, which they discussed with the students.

In 2020, there was no possibility for live presentations in front of an audience. We had to change the original concept. Instead of the first "training" presentation session, we adapted an online course "presenting successfully online" especially for those students, who presented their project work at the end. In the online course, the team members had to work in tandems to gain knowledge in preparing and delivering an online presentation and how to integrate online tools into the presentation process. In four weeks, the presenters received weekly assignments to help them design their presentation slides step by step. Also, SLZ tutors gave feedback on the submitted assignments. Later on, the resulting presentations were given and recorded. By using a gamification approach, e.g., rankings, the tandems competed against each other and strengthened their self-directed learning and presentation skills [2].

\subsection{Team Building}

Another way to meet the challenges of the initial course concept in 2019 was to offer a workshop for the team-leaders of each group. This one-day workshop was designed interactively and included handson activities on how to lead a team. Students should learn to motivate their team, deal with conflict situations, and work cooperatively.

In 2020, the course was specifically designed online for the role of team leaders. The online course lasted 13 days and consisted of three learning units, which were unlocked gradually in the learning environment. The topics of the subsequent learning units consisted of "fundamentals of communication", "team and team development" and "motivation". Each learning unit included video screencasts and assignments. The students could explore the role of team leaders, support each other, and share ideas inside the group of team leaders.

\subsection{Feedback and Monitoring}

Within the framework of constructive conflict management in teams, it is important to recognize early on when problems in a group's dynamics arise, that could influence the outcome of the work. As these processes are hidden to tutors and students do not speak about group problems in public or do not recognize them as such, we again used the tool Live Feedback, this time for a hidden survey. This allowed the students to anonymously report their satisfaction with the teamwork and team dynamics at any time during the team formation and project work process. The students could give feedback regarding the parameters "workload distribution", "online communication", "satisfaction with their role", "professional difficulties", "conflict management" and "online cooperation" regarding their group. This feedback data was stored and timestamped in a database, statistically processed, and displayed by the tool. In this way, the tutors were able to get valuable information about problems or disagreements within the teams at an early stage and address them in the next team meeting. This allows adjusting the work-process for the upcoming time to solve problems. A tutor can see, if students have problems in solving their tasks and can give additional hints or check the understanding early on, before the team meeting. 
We also used this tool during the live presentations in 2019. Students can vote on parameters like presentation style, content, visualization of the contents, and sales arguments for the designed product during the presentations. The votes are recorded and synchronized with timestamps in the video of the presentation so the SLZ tutors can discuss the reason for positive or negative feedback at a given time with the students.

\subsection{Student Tutors}

As mentioned, another big challenge is the huge gap between the professional knowledge required for a design project and the status quo of the students' knowledge at this time of their studies. The project is therefore often overwhelming. With the Live Feedback tool, we are now able to track the occurrence of those professional problems. Since the researchers in their role as tutors do not have enough time to fully support all teams, we hired student tutors. They serve as a coach on "eye-level" and help students inside the online classroom forum. They can give hints and provide insights from their own experience in past semesters. They also encouraged especially female and foreign students, who are often found to step back when it comes to presentations.

\subsection{Collaborative CAD}

In the past, the CAD software "Siemens Solid Edge" was used by the students, which is a classical single-user CAD system, that works with documents on a computer. For collaborative projects, all files have to be shared and synchronized in the group. This created problems, as students are not experienced and often used folders on their computers, that were not shared with the rest of the group. Especially when downloading machine elements like screws or bolts, the students implemented them right from their "Download" folder and forgot to add them to a shared project folder. Due to the need for synchronization, it is also hard to work with multiple people on a project at the same time, as one does not know what anyone else is simultaneously changing in this specific file.

We figured out two possible solutions for this problem: Product Data Management (PDM) or Product Lifecycle Management (PLM) software is designed to collaboratively work on projects, share data to ensure smooth workflows [3]. Another approach is cloud-based CAD [4]. As PLM would also add more complexity to the project work, we decided to solve this problem by using cloud-based CAD software. Over the last years, CAD software like Autodesk Fusion 360 or PTC Onshape became popular. They allow having either the file management in the cloud, while using an app on the own computer like Fusion 360 or working completely browser-based like Onshape. In 2017, after testing the software in a lecture with a smaller group [5], we chose the online-only approach of Onshape, to give the students the easiest possibility to work collaboratively. For each group, we set up a document, where all parts and assemblies could be created and modified. All members of the group have access and can work either remotely or in a group at the same time. Also, the tutors can check the progress of the groups at all times and evaluate the model easier than with paper drawings or images derived from Solid Edge. To track the progress and ensure, that the students cannot modify their project after the final deadline, we use the versioning feature in Onshape as shown in Figure 1.

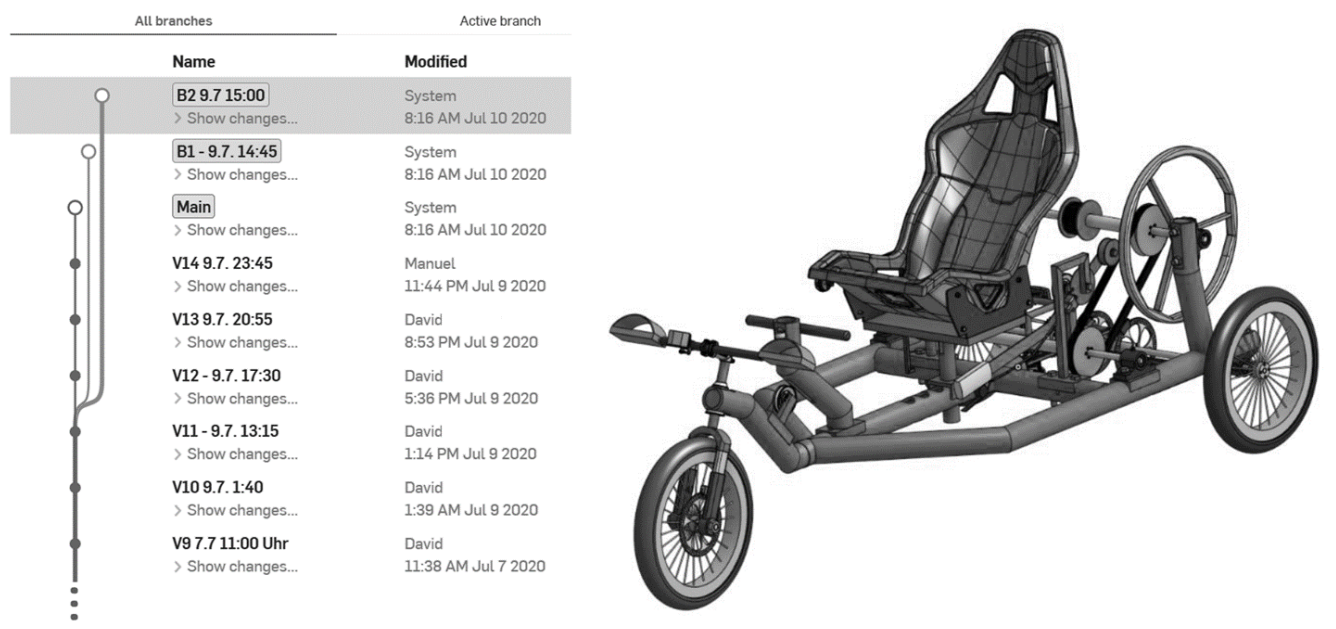

Figure 1. Versioning and project result in Onshape 


\subsection{Virtual Learning Environment}

Virtual learning environments can increase students' self-organisation and self-direction learning abilities. In addition to providing course contents, the learning environment can be didactically structured in a way that promotes generic competencies, while working on subject-related problems [2]. By working in groups, communicative and cooperative skills can be tested, and self-directed learning in groups can be improved [6]. OpenOLAT, based on open software, is the central Learning Management System (LMS) at the TU Kaiserslautern. It bundles various tools and functions to support communicative, coordinative, and cooperative processes. In such a course environment, events can be managed and organized, and materials can be made available. For IDEE, we created a new course environment in OpenOLAT. In the course, the contents of the lectures were provided and used to organize the assignment to the groups. This course was also used to provide access to the monitoring tool Live Feedback, as well as the CAD software Onshape and additional online training materials. For the exchange between students and their student tutors, we used a forum where all questions and answers were to be found. Also, the evaluation took place in OpenOLAT, where all documents had to be uploaded to a submission folder.

\subsection{Switching to online-only}

Although many tools have been used to enable online-only work, lectures, meetings between tutors and students, workshops and presentations required physical presence. As this was not possible due to the Covid19-pandemic, we switched as many contents as possible to online courses. The previous chapters include our approach regarding the workshops and presentations. As for the lectures, we used the principle of a flipped classroom. For some lectures, videos were recorded and provided inside the virtual learning environment, additional lectures were provided by written materials with the possibility for students to make appointments to ask further questions or ask for advice from the tutors.

The meetings, in which every group has to regularly present their progress to get feedback and ask topicrelated questions were transformed into online meetings with the conference tool Skype for Business, which also supports the sharing of screen content. This allowed for broader participation than in the last years since there was no need for physical presence at the campus. The teams could present their current status and by muting / unmuting students, the tutors could very well monitor and control an equal collaboration of every group member.

As for the group work, there was a collaborative working platform for each group inside OpenOLAT, as well as an enterprise chat solution, where the groups could organize themselves. Over the last years, these solutions were partly available, but not used much. In 2020, the usage increased significantly, as the need for well-structured tools became clear to the students and physical meetings as a substitution for these tools were not possible.

As mentioned above, the presentations were recorded by the groups and rated by the tutors. Based on this rating and the performance of the groups during the design process, the project ended with a virtual award ceremony where groups with the best overall performance and the best presentation were honoured with small gifts.

\subsection{Evaluation}

To monitor the student's progress made concerning self-organisation skills, we initiated a voluntary survey at the beginning and the end of the lecture. 66 students participated in the initial survey and 35 in the final survey. To compare the results of both surveys, every student got an individual code. 15 respondents $(n=15)$ participated in both surveys. The following values refer to the 15 respondents which took part in both evaluations. In both surveys, the respondents were asked how they assessed their own presentation, teamwork, moderation, and self-organisation skills. Each item was rated on a 5-point scale (poor $=1$, fair $=2$, good $=3$, very good $=4$, excellent $=5$ It was found that the assessment of competence concerning teamwork and moderation skills increased more than about presentation and self-organisation skills. $26.7 \%$ of the respondents rated their teamwork skills as 'excellent', while in the final survey $50 \%$ of the respondents rated their teamwork skills as 'excellent'. In terms of moderation skills, $35.7 \%$ of the respondents rated their moderation skills as 'very good' or 'excellent' in the initial survey, whereas $50 \%$ of the respondents rated their moderation skills as 'very good' or 'excellent' in the final survey. There are fewer discrepancies in the student's self-assessment concerning presentation and self-organisation skills. In the initial survey, $20 \%$ of respondents rated their presentation skills as 'very good' and none of them assessed these skills as 'excellent', while in the final 
survey $13.3 \%$ chose the category 'very good' and $6.7 \%$ chose the category 'excellent'. This might indicate the participants became more aware of their respective abilities and reflected on them. Selforganisation skills were rated as 'very good' or 'excellent' by $64.3 \%$ of the respondents in the initial survey. In the final survey, the figure was $73.3 \%$. Based on this small group, an increase in assessment was seen in all four skills. This might indicate that the lecture IDEE initiated reflection processes for all topics addressed and made students aware of their performance. In the next run of the lecture IDEE, improvements should be made to increase the return rate of the survey to get more significant results. Also, the project can be further developed to improve presentation, teamwork, moderation, and selforganisation skills.

\section{CONCLUSIONS AND OUTLOOK}

IDEE is an approach to implement practical projects into the early phase of the mechanical engineering curriculum. This is quite overwhelming for students, as they lack professional and personal skills at this point in their studies. Therefore, we designed and implemented several measures to strengthen personal and team competencies, as well as provide more suitable tools to develop and design the group project. In 2019, we used on-site training and online tools as a mix, in 2020, we switched to an online-only approach. By integrating workshops in team-building and presentation, the students have improved their skills significantly. OpenOLAT and Onshape are good solutions for a virtual classroom, in which students can work collaboratively. Online-monitoring is a good way to detect problems early. The key factor for the success of this lecture is the combination of different engineering disciplines with monitoring of the students and opportunities to improve soft skills. At the moment, we plan to transfer the self-directed learning opportunities from IDEE to other lectures early in the curriculum and move the IDEE lecture into a later semester, as the lack of professional skills still is a huge challenge for students. Even with the end of the Covid19-pandemic at sight, there are huge opportunities in the online teaching approach. All teaching materials are available 24/7, tools ensure collaborative work and feedback loops are much shortened. On the other hand, personal and social interaction is more complicated, therefore, in further semesters we will try to include as many online elements as possible and mix these with on-site events for a better social and personal collaboration.

\section{REFERENCES}

[1] Arnold R. Bildung nach Bologna! Wiesbaden: Springer Fachmedien Wiesbaden, 2015

[2] Dietze N., Kuhn A., and Haberer M. Förderung der Selbstlernkompetenz in physischen und visuellen Lernumgebungen: zur Entwicklung und Umsetzung eines "sinnstiftenden" Konzepts. In: Arnold R., Lermen M., and Haberer M. (Hrsg.): Selbstlernangebote und Studienunterstützung. Baltmannsweiler: Schneider Verlag Hohengehren GmbH, 2017 ("Selbstgesteuert, kompetenzorientiert und offen?!", / Rolf Arnold (Hrsg.); Band 3), S. 163-183

[3] Stark J. Product lifecycle management: 21 st century paradigm for product realisation. 2. ed. London: Springer, 2011 (Decision engineering)

[4] Barrie J. Applications for Cloud-Based CAD in Design Education and Collaboration. In: Bingham G., Bohemia E., Kovacevic A., McCardle J., Parkinson B., and Southee D. (Hrsg.): Great expectations: design teaching, research \& enterprise: Proceedings of the 17th International Conference on Engineering and Product Design Education, Loughborough Design School, University of Loughborough, United Kingdom, 3rd-4th September 2015. Glasgow, United Kingdom: The Design Society, 2015 (DS / The Design Society, 82-2), S. 178-183

[5] Eiden A., Apostolov H. and Eigner M. Crowd Engineering - Bringing full cloud CAD into the lab. In: Van den Berg M. and Van Steenbergen M. (Hrsg.): Building an enterprise architecture practice: Tools, tips, best practices, ready-to-use insights. Glasgow, Scotland: The Design Society, Institution of Engineering Designers, 2017 (The enterprise series), S. 170-175

[6] Reinmann-Rothmeier G. and Mandl H. Lernen in Unternehmen. In: Unterrichtswissenschaft 21 (1993), Nr. 3, S. 233-260 